\title{
Predicting developmental processes from evolutionary patterns: a molecular phylogeny of the zebrafish (Danio rerio) and its relatives
}

\author{
AXEL MEYER ${ }^{1}$, PETER A. RITGHIE ${ }^{1}$ AND KAI-ERIK WITTE* \\ ${ }^{1}$ Department of Ecology and Evolution, State University of New York, Stony Brook, New York 11794-5245, U.S.A. \\ ${ }^{2}$ Institute of Limnology, University of Constance, P.O. Box 5560, 78434 Konstanz, Germany
}

\begin{abstract}
SUMMARY
Central to most evolutionary research is the desire to understand the proximate and ultimate factors leading to increased biological diversity. Developmental and evolutionary biology are intimately linked since one factor that limits evolutionary diversification is ontogenetic feasibility to diversify morphology. The connection between these two biological disciplines, although historically recognized, remained long unappreciated. Most work in developmental biology is exclusively concerned with elucidating developmental processes in a small number of model systems, which are then assumed to be representative of a much larger number of species. Typically in this work developmental mutants are induced through mutagens and subsequently mutated genes are identified that are responsible for the altered (loss of function) and wildtype developmental phenotypes. Recently, the zebrafish, Danio rerio, has become one of the most popular model systems in vertebrate developmental biology. We present a DNA-based phylogeny for the zebrafish and 20 of its close relatives. The molecular phylogeny is based on homologous regions of the large (16S) and small (12S) mitochondrial ribosomal RNA genes. We argue that these closely related species of zebrafish, if viewed in an explicitly phylogenetic context, can be treated as natural mutants that lend themselves well to comparative developmental work. Such comparisons might include the study of the developmental mechanisms of somatogenesis in various species of danios that differ in segment numbers (through hybridization, transgenic or other experimental embryological techniques). Based on the extensive zebrafish phylogeny we explore the connection between ontogeny and phylogeny and argue that evolutionary biology cannot only test plausible historical scenarios, but might also be able to predict and help characterize which differences in developmental processes are responsible for differences between species and more general evolutionary trends.
\end{abstract}

\section{INTRODUGTION}

Evolutionary biologists are interested in discovering and explaining evolutionary patterns in the bewildering diversity of species. Developmental biologists elucidate ontogenetic processes that are at the basis for the diverse Baupläne that differentiate phyla. Obviously, developmental processes evolve just like all other features of species and can be the subject of evolutionary inquiry in themselves. In trying to understand biological diversification, albeit at different levels of inquiry, is where the interests of developmental biologists and evolutionary biologists meet. Nonetheless, most evolutionary research treats development like a black box and most developmental biologists have little appreciation for evolution's contribution to the understanding of development. Moreover, the fact that developmental biologists think about processes and evolutionary biologists predominantly about patterns has kept the two biological disciplines non-

* Present address: Max-Planck-Institut für Entwicklungsbiologie, Spemannstr. 35, 72076 Tübingen, Germany. conversant in each other's language. Historically, the link between ontogeny and phylogeny was well appreciated but the idea then lay dormant for almost a century. Early on, it was thought that the ontogeny of an organism 'recapitulates' its evolutionary history but it is now clear that, at best, it only progresses from the 'general' to the 'specialized' (von Baer 1828, 1864; Haeckel 1866; reviewed in Gould 1977). Only recently was the connection between development and evolution re-established by evolutionary biologists rediscovering developmental mechanisms as a factor in shaping and constraining the evolution of adult phenotypes (for reviews see: Baldwin 1902; Waddington 1957; Gould 1977; Alberch et al. 1979; Goodwin et al. 1983; Raff \& Kaufman 1983; Arthur 1984; Brooks \& McLennan 1991; Harvey \& Pagel 1991; Wray \& Raff 1991; Hall 1992; Wray 1992; Wake 1995) and by developmental biologists recognizing the importance of evolution for their understanding of developmental processes (for example: Sommer \& Tautz 1993; Barinaga 1994; Patel 1994). Recent technical and analytical advances in both 
disciplines might now allow for rewarding, mutual enlightenment and faster progress in understanding both sets of questions, viewing them not as separate but rather as intrically connected issues.

The comparative method has long been favoured in evolutionary biology for answering many different kinds of questions (e.g. on adaptation) (see, for example, Ghiselin 1984; see references in Harvey \& Pagel 1991 and Brooks \& McLennan 1991). The approach is to study the evolution of phenotypic characteristics of species based on knowledge of the phylogenetic relationships among them. At the heart of the comparative method is a firmly established phylogeny based on which the tracing of character evolution, developmental or otherwise, 'up and down the tree' can be conducted. The recent resurgence of interest in the comparative method coincided with the development of rigorous statistical and cladistical approaches to reconstruct phylogenetic relationships and character evolution (see, for example, Maddison \& Maddison 1992) and the arrival of the polymerase chain reaction (PCR) as a powerful tool easing the gathering of data for molecular phylogenetic work. The combination of these new methods has raised the hope of being able to establish reliable phylogenetic estimates and hence allow for rigorous testing of evolutionary hypotheses. However, both highly influential reviews on the comparative method in evolutionary biology (Brooks \& McLennan 1991; Harvey \& Pagel 1991), otherwise complementary and comprehensive, fail to mention the capacity of the comparative method to predict developmental processes from evolutionary patterns. Those reviews only consider the ontogeny-phylogeny connection in the context of using the knowledge of ontogeny in assigning 'polarity' (ancestral or derived) to character state transformations, knowledge that aids in the 'rooting' of phylogenetic trees.

The establishment of powerful molecular genetic tools enabled developmental biologists to identify developmental control genes and some of their interactions. Further, the timing of their expression which codes for aberrant and wildtype developmental patterns was characterized, which permits the study of the underlying genetic basis of ontogeny with stunning clarity and beauty (see, for example, Nüsslein-Volhard \& Wieshaus 1980; reviewed in Lawrence 1992). Because of the need for large-scale mutation screens and other time-consuming and laborious groundwork, developmental investigations can typically focus on only a small number of model systems. Developmental patterns and processes from those model systems are then assumed to be typical for a much larger number of species, e.g. lessons from 'the vertebrate model' are hoped to apply to all vertebrates including man. The major model organisms in developmental biology are widely spread across the evolutionary tree of animals; the most recent addition as a promising model system in vertebrate development is the zebrafish (Danio rerio) (figure 1).

The methodologies of evolutionary and developmental biology are rarely combined; what predictive power the comparative method might hold for de-

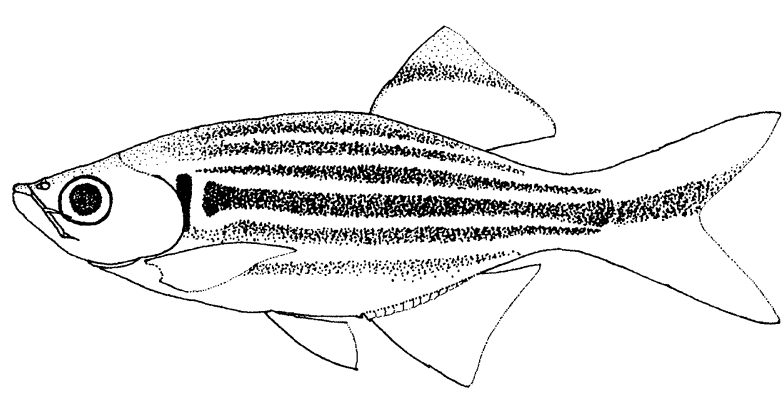

Figure 1. Outline of a danio of the Danio devario clade. Indicated are some of the colorational features of the danios that vary between species. The evolution of these traits are dealt with in detail in K.-E. Witte \& A. Meyer (in preparation).

velopmental investigations is largely unexplored. Although developmental biologists recently acknowledged the importance of evolution, e.g. by doing comparative developmental studies, their acceptance of the relevance of evolution for understanding development has been incomplete and has not sufficiently recognized the fact that the comparative method can predict the likely condition in common ancestors and thereby elucidate the evolution of developmental mechanisms. Typically, only pairwise comparisons of developmental processes have been made; yet these comparisons always yield highly interesting and often surprising results about evolutionary differences in development (e.g. Drosophila and Tribolium (Sommer \& Tautz 1993), nematodes (Sommer \& Sternberg 1994), early determination of polarity in Drosophila and Caenorhabditis (see references in Kimble 1994)). However, pairwise comparisons have inherent limitations and do not provide nearly as much information as comparisons in an explicitly phylogenetic context (see, for example, Garland \& Adolph 1994). Few developmental studies have gone beyond the pairwise comparison to include phylogenetic and ontogenetic information for closely related taxa, e.g. Drosophila (DeSalle \& Grimaldi 1993; Luk et al. 1994). Very few phylogeny-based developmental studies exist (for insect-arthropod comparisons see Patel (1994) and references therein; for sea urchins see Wray \& Bely (1994) and references therein) and these tend to be among very distantly related species.

Some 'comparative' experimental studies involve either swapping of promoters or altering the gene order of Hox genes in the homeobox cluster among distantly related species. Comparisons of developmental patterns and processes among closely related species can provide insights that are not easily gained from comparisons among distantly related species. For example, the elucidation of the developmental function of a particular Hox gene or other developmental control genes might be investigated e.g. by investigating its effect in a different species through transgenic experiments. Closely related species share more genes and their genes are more similar than those among distantly related species since they share more recent common ancestors. The study of the timing of expression of developmental genes (e.g. the homology of control elements of gene expression and their network of 
interactions) will potentially provide new insights into the genetic basis of particular developmental traits. The expression of a particular gene in a foreign species is always confounded by a network of foreign regulatory genes and differently structured networks of interactions among those genes. Therefore, if transgenic organisms were produced among closely related species one might be able to quantify this effect more precisely by taking the evolutionary distance and, more importantly, relationships among the experimental donor and recipient species into consideration. In essence, through phylogenetic knowledge, one might be able to better control for the genetic background (here to mean cascading effects and networks of interactions of control elements) in which a particular foreign gene is expressed.

\section{(a) The zebrafish model system}

The zebrafish is now one of the most widely used model systems of lower vertebrates and literally hundreds of publications on its development and biology have already been published (Westerfield 1989). The developmental biology community welcomed the zebrafish model with open arms and many research programmes were switched from Drosophila to Danio. For a model to be useful one needs large numbers of mutants that disrupt embryonic development and needs to isolate the mutant genes that are responsible for ontogenetic effects. The speed of the characterization of early zebrafish development by mutational analyses which started only ten years ago (Walker \& Streisinger 1983) is breathtaking (e.g. reviewed in: Kimmel 1989; Barinaga 1990; Concordet \& Inham 1994; Dove 1994; Kahn 1994; NüssleinVolhard 1994; Solnica-Krezel et al. 1994; Driever et al. 1994; Mullins et al. 1994).

Drosophila species would be a potentially appropriate model system to combine transgenic or hybridization approaches in comparative developmental studies, since the development, genetics and phylogeny of Drosophila melanogaster are so well known (DeSalle \& Grimaldi 1993). However, even closely related species of Drosophila typically cannot be hybridized. Among closely related species of vertebrates, these kinds of comparative experimental embryological studies within a phylogenetic framework might best be made between different species of danios (figure 1), a group of fishes that includes the zebrafish. In general, all species within the Danio rerio clade and within the Danio devario clade can be hybridized in aquaria. However, crossings between species of the $D$. rerio clade and species of the $D$. devario clade are rare and usually hybrids are sterile; however, reports on fertile hybrids and successful backcrosses can be found (table l).

The biggest advantage of the zebrafish over Drosophila is that it is a vertebrate and therefore its development has more immediate relevance to humans. The other advantages of zebrafish compared with Drosophila have to do more with its development than its genetics: compared with Drosophila it has a long generation time. However, many attributes of the biology of the zebrafish make it a desirable model system, e.g.: (1) it is easily available (in pet stores) throughout the world; (2) it is easy to breed in captivity; (3) its generation time is only 3-4 months; (4) females will lay eggs almost daily, which ensures a steady supply of embryos; (5) it has transparent eggs and clear embryos; (6) development proceeds rapidly and synchronously; (7) development occurs outside the female's body; (8) zebrafish are small (they mature at about $30-40 \mathrm{~mm}$ in length) which allows one to keep thousands of individuals in a small space; (9) homozygous diploid strains can be produced (Streisinger $e t$ al. 1981), facilitating genetic studies such as the discovery of recessive mutations and linkage analysis, and haploid embryos (facilitating mapping) and parthenogenetic (homozygous gynogenetic lines) diploids can be easily produced; (10) sperm can be frozen; (11) the recent publication of an RAPD-marker based genomic map for zebrafish will facilitate the future mapping of genes (Postlethwait et al. 1994). Most of the advantages of Danio rerio as model system also apply to species closely related to it.

\section{(b) Systematics and phylogeny of the zebrafish and its close relatives}

Zebrafish Danio rerio and its relatives belong to the family Cyprinidae in the order Cypriniformes; cyprinid diversity is greatest in Asia. Howes (1991) estimates that there are 200 genera and 1700 species, which makes this family one of the most species-rich of all vertebrates. Most cyprinids are limited to freshwater where they dominate all continental fish faunas but those of South America and Australia where they are absent. Nearly 50 genera (K.E.W.), related to danios and rasboras, are assigned to the subfamily Danioninae (Rainboth 1991).

The zebrafish and closely related danios are herein provisionally included in the genus Danio. The small danios have usually been referred to as Brachydanio (see, for example: Weber \& Beaufort 1916; Myers 1935) but this has not been followed by all authors (Chu 1981). Some valid taxa have been overlooked or are currently regarded as synonyms.

The interest of developmental biologists in the zebrafish has resulted in more work on the classification and phylogeny of danios. However their morphology does not provide many characters that can be used for the cladistic determination of a fully resolved phylogeny. Traditionally, systematists have used phenotypic, often morphological or karyological, characters to establish classifications and phylogenetic relationships. Molecular approaches, through the phylogenetic analysis of orthologous DNA sequences to establish phylogenetic relationships, have recently provided a successful alternative approach. Mitochondrial DNA in particular has been widely used to establish relationships among closely related species (reviewed, for example, in Meyer 1993b). Meyer et al. (1993) presented the first molecular phylogeny of the zebrafish. An enlargement of this molecular phylogeny in terms of numbers of species and number of genes and base pairs sequenced is presented here. It is intended to serve as an outline of how knowledge of phylogenetic 
Table 1. Danio hybrids

(Female $\times$ male; * indicates that sex of parents is uncertain; - indicates that no information is available.)

\begin{tabular}{|c|c|c|c|}
\hline cross & type & viable & reference \\
\hline \multicolumn{4}{|l|}{ intrageneric } \\
\hline D. 'franke $i$ ' $\times D$. rerio & artificial insemination & 一 & Kavumpurath \& Pandian (1992) \\
\hline D. 'frankei' $\times D$. rerio & aquarium hybrids & several backcrossings & Petrovicky (1966) \\
\hline D. 'frankei' $\times D$. rerio & aquarium hybrids & F2 and F3 obtained & Housz (1964) \\
\hline D. albolineatus $\times D$. rerio & aquarium hybrids & 一 & $\begin{array}{l}\text { Schreitmüller }(1926)^{*} \text {; van Haut } \\
\quad(1953)\end{array}$ \\
\hline D. albolineatus $\times D$. rerio & artificial insemination & - & Frankel (1977) \\
\hline D. albolineatus $\times$ D. rerio $*$ & aquarium hybrids & - & Schreitmüller (1925) \\
\hline D. rerio $\times D$. albolineatus & artificial insemination & 一 & Frankel (1977) \\
\hline D. nigrofasciatus $\times D$. 'frankei' & artificial insemination & - & Frankel (1979) \\
\hline $\begin{array}{l}\text { D. nigrofasciatus } \times \\
\text { D. albolineatus } *\end{array}$ & \multicolumn{2}{|c|}{ D. albolineatus* } & Meinken (1925) \\
\hline D. nigrofasciatus $\times D$. rerio & artificial insemination & died within a week & Frank (1968); Frankel (1978) \\
\hline D. rerio $\times D$. nigrofasciatus & aquarium hybrids & - & \\
\hline D. rerio $\times D$. cf. aequipinnatus* & single aquarium hybrid & - & Schreitmüller (1926) \\
\hline \multicolumn{4}{|l|}{ intergeneric hybrids } \\
\hline $\begin{array}{l}\text { Danio spp. } \times \text { Tanichthys } \\
\text { albonubes* }\end{array}$ & 一 & 一 & Meinken (1963) \\
\hline \multicolumn{4}{|l|}{ interfamilial hybrids } \\
\hline $\begin{array}{l}\text { D. rerio } \times \text { Paramisgurmus } \\
\text { dabryanus }\end{array}$ & fusion of eggs & died early & Zhang et al. (1992) \\
\hline
\end{tabular}

relationships among closely related species can increase the power of hypothesis testing in the study of the development-evolution relationship.

\section{MATERIALS AND METHODS}

Table 2 lists species used in this study. Specimens marked with an asterisk were commercially obtained from several localities (Berkeley, Albany and San Francisco in California; Long Island in New York; Lübeck, Hamburg and Munich in Germany). Two specimens were a gift from the Kimmel laboratory at the University of Oregon and two a gift from M. R. Palmer, Virginia State University (Danio of. tweediei and $D$. 'frankei'). The other specimens were collected in the wild and all specimens are deposited as vouchers in the research collection of K.E.W. The specimen of Tanichthys albonudes corresponds to the typical Cantonese taxon. Typically, one specimen per species was sequenced (but see below). The sequences of the carp (Cyprinus carpio) were obtained from GenBank (accession no. X61010). The status of $D$. frankei as a valid biological species is disputed (see, for example, Kavumpurath \& Pandian 1992). Techniques for data collection of DNA sequences of the mitochondrial $16 \mathrm{~S}$ (about 520 base pairs) and 12S (about 270 base pairs) ribosomal RNA genes and their phylogenetic analysis have been described before (Meyer et al. 1993; Meyer 1993a,b).

Table 2. Classification of cyprinid species used in this study

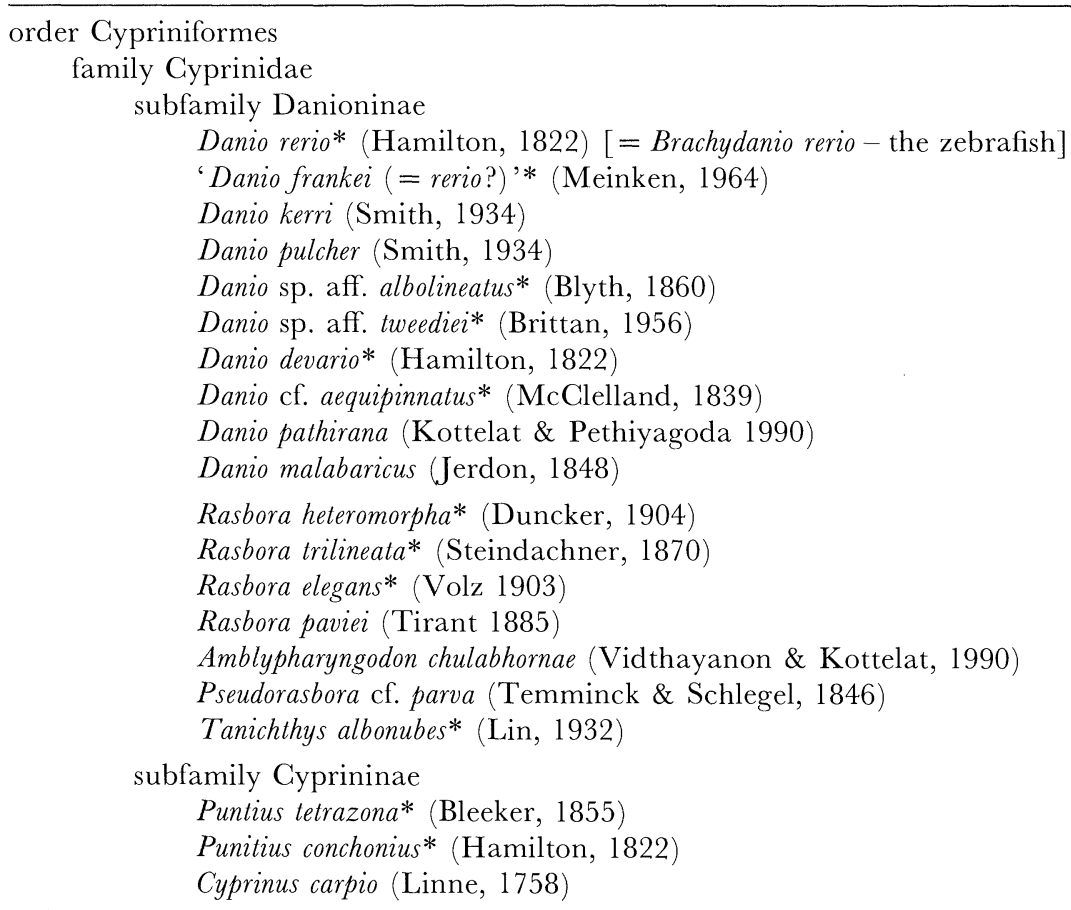


Sequences determined here are available in GenBank (accession numbers U21370-U21387, U21553-U21544 and L14487-L14499). The last are from our previous study (Meyer et al. 1993).

\section{RESULTS}

Our estimate of the evolutionary relationships among the zebrafish and its relatives is corroborated by both parsimony (Swofford 1991) and neighbourjoining (Saitou \& Nei 1991) phylogenetic methods and most branches are supported with high bootstrap confidence (Felsenstein 1985) (figure 2). Overall, the molecular phylogeny obtained agrees with the current classification of these species (table 2). Taxonomic and phylogenetic implications and the evolution of colorational differences between these species will be discussed elsewhere (K.-E. Witte \& A. Meyer, in preparation). No intraspecific differences in DNA sequences within $D$. sp. aff. albolineatus and $D$. malabaricus were found and only one transition mutation among the four specimens of $D$. rerio and three specimens of $D$. franke $i$ was detected. It should be noted that we are unsure of the species status of Danio frankei. Specimens of this latter 'species' differ from Danio rerio by only one transition substitution, and this position also varied within $D$. rerio proper and was variable between specimens of $D$. frankei.

The phylogeny (figure 2) derived from the $12 \mathrm{~S}$ and $16 \mathrm{~S}$ sequences supports the sister group relationships of

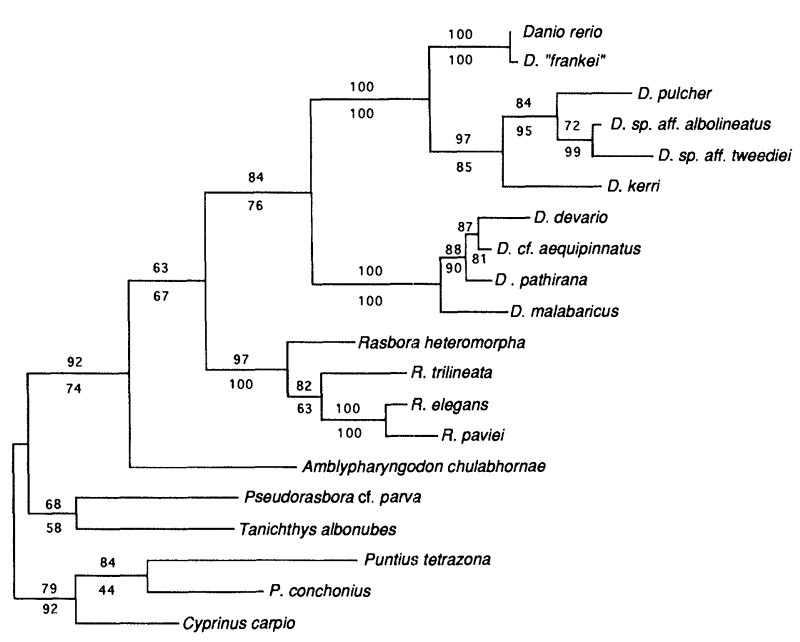

Figure 2. Molecular phylogenetic relationship of the zebrafish to its closest relatives. Shown is $(a)$ the shortest (parsimonybased) tree, with branch lengths proportional to the number of inferred substitutions, with bootstrap (Felsenstein 1985) support values based on 100 replicates with the neighbourjoining (Saitou \& Nei 1987) (above the branches) and parsimony (Swofford 1991) methods (values below the branches). Almost identical shortest phylogenetic estimates were established by the neighbour-joining method (Saitou \& Nei 1987) and maximum parsimony methods (PAUP; Swofford 1991). The maximum parsimony method (without differential weights for transitions and transversions, calculated with PAUP; Swofford 1991) found a single most parsimonious tree (length 661 steps, consistency index (CI) 0.584 , GI excluding uninformative characters 0.396). Two species of the genus Puntius and the carp (Cyprinus carpio) were designated as outgroups. danio species that were previously placed into the now obsolete genus Brachydanio with other danios. Species of the genus Rasbora are the sister group to the danios, the genus Danio in a wide sense.

\section{DISGUSSION}

At first glance, developmental and evolutionary biologists seem to ask different kinds of questions. Yet their approaches can be reciprocally elucidating. For developmental biologists, there are several ways in which knowledge about the evolution and specifically the phylogenetic relationships among model systems can aid in the understanding of developmental processes (see, for example: Kellog \& Shaffer 1993; Meyer et al. 1993).

\section{(a) Questions of common interest to evolutionary and developmental biologists}

Evolutionary biologists, as one among other questions, would like to be able to define the embryological capabilities and limitations that are responsible for shaping the observed patterns of morphological evolutionary diversification among different phyla. At the species level, one might ask which developmental differences will result in species-specific differences in adult phenotypes or conversely one might investigate the developmental similarities or differences between species that seem to display convergently evolved phenotypes.

Convergence, the independent occurrence and evolution of morphological, or other types of phenotypic, features can only be discovered when the phylogenetic relationships among species are known. It is an evolutionarily interesting problem for which knowledge of the developmental basis would be important. For example, it is conceivable that convergence might be brought about by different means, e.g. the same ontogenetic mechanism was reactivated or reinvented or an entirely different ontogenetic pathway converging onto the same adult phenotype was discovered. Also atavism, the evolutionary reoccurrence of ancestral morphological characteristics in a derived group, is an evolutionary phenomenon that might have a similar developmental basis as convergence; however, this is unexplored and requires more comparative developmental work.

At the developmental level, convergence cannot be predicted and can only be discovered if comparative embryological data are collected; unfortunately, this will typically not be the case because of the focus on a small number of model organisms. Recent data seem to show an astonishing conservation (or convergence?) in morphogenetic activity of hedgehog and its paralogues and presumed homologues (see, for example, Fietz et al. 1994). Nonetheless, there are known instances where fundamentally different embryological trajectories result in phenotypically similar adults (e.g. in congeneric sea urchins (Wray \& Raff 1991)) and conversely similar developments can result in strikingly different adult phenotypes as is illustrated by the many instances 
of large morphological differences among closely related species. For example, the surprisingly large differences among some congeneric species of sea urchins in larval morphology and life history (direct versus indirect development) might indicate that a few molecular changes (that arose within short geological time spans) can produce strikingly different phenotypes (Strathmann et al. 1992; Raff 1992; Wray \& Bely 1994). Developmental and phenotypic differences are not necessarily tightly correlated with phylogenetic distance.

Homology is an important and still unsolved problem (for review see Hall 1994) in evolutionary biology at the phenotypic (developmental mechanisms) and the genetic level (Patterson 1988). Some insights into these issues are likely to come only from comparisons between distantly related model systems; others can be derived more appropriately from comparisons among closely related species. For example, phylogenetically fine-grained comparisons might provide a powerful tool to experimentally determine the function of particular developmental control genes. Homology among developmental control genes is often more problematic to assess among distantly related species particularly for families of genes that underwent repeated duplication events, such as homeobox and hedgehog genes (see, for example: Scott \& Carroll 1987; Kappen et al. 1989; Murtha et al. 1991; Krauss et al. 1992; Marx 1992; Tabin 1992; Schubert et al. 1993; Dick \& Buss 1994; DeRobertis 1994; Gehring 1994; Lee et al. 1994). Homology of genes among distant species, such as Drosophila and zebrafish, is often ambiguous since it is often inferred only through 'functional homology' (a misnomer that does not necessarily imply true homology of two genes). Several Hox genes have already been isolated from zebrafish and other fishes (see, for example: Fjosse et al. 1988, 1990; Runstadler \& Kocher 1991). However, the homology of these zebrafish genes is often not unambiguously determined because of the conserved nature of the homeobox domain and the types of approaches used (typically PGR-based studies that amplify a subset of antp-class genes) and the lack of a map of the zebrafish Hox gene cluster and sequencing study on the complete homeobox cluster. For several reasons, 'functional homology' is misleading, e.g. since in multigene families potentially 'homologous' genes might be similar in sequence and function in different species, but this might be due to convergence rather than true ancestral relationships and needs to be established by a genealogical analysis of these genes. It would appear that much insight into the functional aspects (both cellular and molecular) of developmental evolution could be gained if several closely related species were compared, making the search for and identification of truly homologous genes simpler.

The production of transgenic fish for homeobox genes within a phylogenetic framework of closely related species might allow one to determine the effects of varying genetic backgrounds, i.e. the effects of the expected divergence of networks of control elements. The expectation would be that homologous genes would, under foreign genetic control of closely related species, be more likely to have less of a different phenotypic effect than in a more distantly related species where control elements are more likely to differ. Zebrafish pax genes are related to mouse paired-box genes (Krauss et al. 1991, 1992) and their expression patterns are similar in the developing brain, delineating the basic subdivision of the vertebrate brain into midbrain and hindbrain. This similarity in the two species suggests conservation over large evolutionary distances. Like Hox genes, genes containing the paired box are capable of sequence-specific DNA binding and regulate transcription and hence activity of other genes. However, the evolutionary conservation of Hox genes in terms of structure of expression in terms of timing and of pattern are not found for all developmental genes of importance or even all $H o x$ genes. Moreover, the regulation of expression of transgenes is often surprisingly unpredictable and even among relatively closely related species control elements might differ substantially (see, for example, Moav et al. 1993).

Murray (1989) demonstrated that a change in a single parameter of the reaction diffusion mechanism may be all that is required for a developmental switch between stripes and spots. The most closely related species to the zebrafish is the leopard danio (Danio frankei), which instead of three lateral stripes has spots. These two species are easily hybridized and reciprocal hybrids have an intermediate coloration where stripes blend with spots as would be expected for codominant alleles (Kavumpurath \& Pandian 1992). Hybridization experiments among closely related species of danios might be one inroad to studying the ontogeny (and its genetic control) and phylogeny of pigmentation patterns (K.-E. Witte \& A. Meyer, in preparation).

Development is likely to be conserved during early embryogenesis and usually only in the latter stages of development will species-specific differences emerge. Unfortunate for evolutionary biologists interested in adult phenotypes is the fact that nearly all of the zebrafish developmental work has focused on mutations before the sixth day of the embryo where few differences among closely related species are expected to arise. However, those are the differences that evolutionary biologists are typically interested in. However, some morphological differences, e.g. difference in numbers of caudal fin rays or numbers of vertebrae, can differ between closely related species and are laid down early in development. These developmental characteristics and their underlying genetic bases are currently being investigated.

\section{(b) The study of somitogenesis in zebrafish: an example of the potential use of a phylogeny and 'natural mutants' in experimental embryology}

Three types of vertebrae are found in cyprinid fishes. Most anteriorly lie the four cervical vertebrae which are heavily modified to accommodate the Weberian apparatus. They are followed by typically 10 or 11 abdominal vertebrae in the fishes of the genus Danio followed by 16-19 caudal vertebrae (vertebrae formula: 4, 10-11, 16-19). The number of vertebrae 


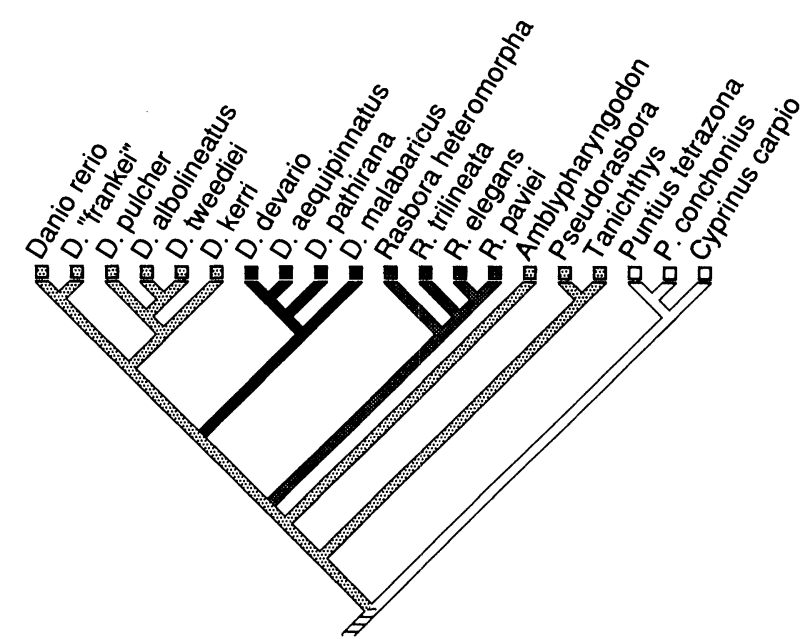

Figure 3. Character state reconstruction (MacClade: Maddison \& Maddison 1992) of the number of trunk vertebrae in danios is more different $(12-13)$ in species of the Danio devario clade than in the Danio and Rasbora species (10-11, 11-12) and both Amblypharyngodon and Tanichthys also have 11 abdominal vertebrae. Based on these differences, a difference in terms of developmental mechanisms of somatogenesis between species of Danio rerio and the Danio devario clade might be expected. However, they are more closely related to each other than species of the zebrafish are to other cyprinid fishes that are identical in abdominal vertebrae number. The introduction of foreign genes into the zebrafish might allow us to determine which developmental mechanisms and genes are causing the differences in the number of somites between it and its relatives.

toolbox of the developmental biologist. These interspecific differences might help to study how somite number is determined and how, on a molecular genetic corresponds to the number of myotomes in the fish. Species in the genus Danio, including the zebrafish, typically have a total of 30-34 vertebrae. Interestingly, the total number of vertebrae in zebrafish species of the Danio rerio clade is always less (30-34 vs 35-37) than that of the larger species of the Danio devario clade (their vertebrae formula is $4,12-13,19-20)$. The vertebrae formula for Rasbora heteromorpha included in this study is $4,11-12,14-15=30-31$, for Tanichthys it is $4,11,18$ $=33$ and for Amblypharyngodon is 4, 11, $18=33$.

Based on our phylogeny (figure 3 ) it becomes clear that the evolution of vertebrae and somite number and somatogenesis can be traced based on the evolutionary relationships among these fishes. Since species of Danio devario clade consistently have a higher number (particularly of abdominal vertebrae) than other Danio species in these meristic characteristics they are essentially natural mutants that might be available for experimental embryological research. The phylogeny might suggest several experiments (e.g. hybridizations or production of transgenics of e.g. engrailed which is found at somite boundaries) between species of the Danio rerio clade or members of the Danio devario clade. These could be used to determine the molecular genetic and morpho genetic differences between these species in terms of laying down the number of somites, particularly those that will develop into the abdominal vertebrae. Obviously, these natural mutants do not deny the importance of artificially induced mutations in determining the basis for wildtype and aberrant development, but natural mutations might augment the level, species differences (in somite number and potentially other characteristics) are brought about. These differences might be caused by simple differences in the responsiveness in control elements to a signal peptide such as retinoic acid. Retinoic acid is a crucial signalling molecule in vertebrate pattern formation as well as regeneration (Joore et al. 1994; Smith et al. 1994; White et al. 1994). Many aspects of genes that control development are highly conserved across large evolutionary distances, e.g. the retinoic acid control of the expression patterns of some of homeobox genes remains unchanged between fish and birds (Marshall et al. 1994). Despite this conservation in sequence similarity and function, the morphology obviously differs dramatically between these species.

The zebrafish phylogeny also provides a gauge of similarity in genetic background that is not available in simply pairwise comparisons. Evolutionarily closely related species will share more genes, and their genes are likely to be more similar in DNA sequence and arrangement on chromosomes. This argument might also apply to the cascade and networks of the developmental control genes, but how such a network evolves is not known, e.g. whether elements are added or the communication between the elements becomes more complex. The phylogeny of zebrafish species might aid in the study of regulatory sequences (e.g. in introns) that control the expression of zebrafish control genes. Many examples show that the evolution of developmental mechanisms and adult phenotypes do not proceed at a regular pace and that large morphological differences may be caused by small genetic differences. Hence, to infer descent and phylogeny from the phenotype can be misleading since the rate of morphological evolution can be so variable. Molecules tend to be more impartial tracers of evolutionary relationships.

The practical advantages of zebrafish as a model system that have made it so popular in developmental biology apply to many other closely related species of fishes. Our phylogeny of the zebrafish is meant as an invitation to study the biology of cyprinid fishes within a comparative evolutionary framework and to use the genetic variation contained in species other than the zebrafish itself to facilitate the study of zebrafish development.

We thank David Wake, Greg Wray and Alexa Bely for discussion and for sharing unpublished information. We are grateful to the National Science Foundation, U.S.A., for support (grants DEB-8918027, BSR-9107838 and BSR9119867 to A. M.). K. E.W. thanks Professor J. Schwoerbel for providing laboratory facilities and K. Tegelhütter for a specimen of $D$. pathirana.

\section{REFERENGES}

Alberch, P., Gould, S. J., Oster, G. F. \& Wake, D. B. 1979 Size and shape in ontogeny and phylogeny. Paleobiology 5 , 296-317.

Arthur, W. 1984 Mechanisms of morphological evolution. Chichester: John Wiley. 
Baer, K. E. von 1828 Entwicklungsgeschichte der Thiere: Beobachtungen und Reflexion. Königsberg: Bornträger.

Baer, K. E. von 1864 Reden gehalten in wissenschaftlichen Versammlungen. St Petersburg: Karl Röttger.

Baldwin, J. M. 1902 Development and evolution. New York: Macmillan.

Barinaga, M. 1990 Zebrafish: swimming into the mainstream. Science, Wash. 250, 34-35.

Barinaga, M. 1994 Looking to development's future. Science, Wash. 266, 561-564.

Brooks, D. R. \& McLennan, D. A. 1991 Phylogeny, ecology, and behaviour: A research program in comparative biology. Chicago: Chicago University Press.

Concordet, J.-P. \& Ingham, P. 1994 Catch of the decade. Science, Wash. 369, 19-20.

Chu, X.-I. 1981 A preliminary revision of fishes of the genus Danio from China. Zool. Res. 2, 145-156.

De Robertis, E. M. 1994 The homeobox in cell differentiation and evolution. In Guidebook to the homeobox genes. (ed. D. Duboule), pp. 13-23. Oxford: Oxford University Press.

DeSalle, R. \& Grimaldi, D. 1993 Phylogenetic pattern and developmental process in Drosophila. Syst. Biol. 42, 458-475.

Dick, M. H. \& Buss, L. W. 1994 A PCR-based survey of homeobox genes in Ctenodrilus serratus (Annelida: Polychaeta). Molec. Phyl. Evol. 3, 146-158.

Dove, W. F. 1994 Transparent vertebrates and their genetic images. Genetics, Princeton 137, 339-341.

Driever, W., Stemple, D., Schier, A. \& Solnica-Krezel, L. 1994 Zebrafish: genetic tools for studying vertebrate development. Trends Genet. 10, 152-159.

Felsenstein, J. 1985 Confidence limits on phylogenies: an approach using the bootstrap. Evolution 39, 783-791.

Fietz, M. J., Concordet, J.-P., Barbosa, R., Johnson, R., Krauss, S., McMahon, A. P., Tabin, C. \& Ingham, P. W. 1944 The hedgehog gene family in Drosophila and vertebrate development. Development (suppl.) pp. 43-51.

Fjosse, A. et al. 1988 Molecular cloning and characterization of homeobox-containing genes from Atlantic salmon. Gene 62, 141-152.

Fjose, A., Eiken, H. G., Njølstad, P. R., Molven, A. \& Hordvik, I. 1990 Homeobox sequences of Atlantic salmon (Salmo salar) and zebrafish (Brachydanio rerio). Aquaculture 85, 51-60.

Frank, S. 1968 Kreuzung von Zebrabärbling mit Tübfelbärbling (Danio rerio $\times$ nigrofasciatus). Aquaterra 5, 95-97.

Frankel, J. S. 1978 Gene activation of alcohol dehydrogenase in danio hybrids. J. Hered. 69, 57-58.

Frankel, J. S. 1979 Inheritance of spotting in the leopard danio. J. Hered. 70, 287-288.

Garland, T. Jr \& Adolph, S. G. 1994 Why not to do twospecies comparative studies: limitations on inferring adaptation. Physiol. Zool. 76, 797-828.

Gehring, W. J. 1994 A history of the homeobox. In Guidebook to the homeobox genes (ed. D. Duboule), pp. 3-10. Oxford: Oxford University Press.

Ghiselin, M. T. 1984 The triumph of the Darwinian method. Chicago: University of Chicago Press.

Goodwin, B. G., Holder, N. \& Wylie, G. G. (eds) 1983 Development and evolution. Cambridge: Cambridge University Press.

Gould, S.J. 1977 Ontogeny and phylogeny. Cambridge: Harvard University Press.

Haeckel, E. 1866 Generelle Morphologie der Organismen: Allgemeine Grundzüge der organischen Formen-Wissenschaft, mechanisch begründet durch die von Charles Darwin reformierte Descendenz-Theorie. Berlin: George Riemer.
Hall, B. K. 1992 Evolutionary developmental biology. London: Chapman \& Hall.

Hall, B. K. 1994 Homology: the hierarchical basis of comparative biology. San Diego: Academic Press.

Harvey, P. H. \& Pagel, M. D. 1991 The comparative method in evolutionary biology. Oxford: Oxford University Press.

Holland, P. 1992 Homeobox genes in vertebrate evolution. BioEssays 14, 267-273.

Housz, F. M. I. 1964 Was ist Brachydanio frankei? Aqua. terr. Zeitschr. 38.

Howes, G. 1991 Systematics and biogeography: an overview. In Cyprinid fishes: systematics, biology and exploitation. (ed. I. J. Winfield \& J. S. Nelson), pp. 1-28. New York: Chapman and Hall.

Joore, J., van der Lans, G. B. L. J., Lanse, P. H., Vervaart, J. M. A., Zivkovic, D., Speksnijder, J. E. \& Kruijer, W. 1994 Effect of retinoic acid on the expression of retinoic acid receptors during zebrafish embryogenesis. Mech. Devl. 46, 137-150.

Kahn, P. 1994 Zebrafish hit the big time. Science, Wash. 264, 904-905.

Kappen, C., Schughart, K. \& Ruddle, F. H. 1989 Two steps in the evolution of Antennapedia-class vertebrate homeobox genes. Proc. natn. Acad. Sci. U.S.A. 86, 5459 5463.

Kavumpurath, S. \& Pandian, T. J. 1992 Hybridization and gynogenesis in two species of the genus Brachydanio. Aquaculture 105, 107-116.

Kellog, E. A. \& Shaffer, H. B. 1993 Model organisms in evolutionary studies. Syst. Biol. 42, 409-414.

Kimble, J. 1994 An ancient molecular mechanism of establishing embryonic polarity? Science, Wash. 266, 577578.

Kimmel, G. B. 1989 Genetics and early development of zebrafish. Trends Genet. 5, 283-288.

Krauss, S., Concordet, J.-P. \& Ingham, P. W. 1993 A functionally conserved homolog of the Drosophila segment polarity gene is expressed in tissues with polarizing activity in zebrafish embryos. Cell 75, 1431-1444.

Krauss, S., Johansen, T., Korzh, V. \& Fjose, A. 1991 Expression pattern of zebrafish pax genes suggest a role in early brain regionalization. Nature, Lond. 353, 267-270.

Krauss, S., Maden, M., Holder, N. \& Wilson, S. W. 1992 Zebrafish pax $[\mathrm{b}]$ is involved in the formation of the midbrain-hindbrain boundary. Nature, Lond. 360, 87-89.

Lawrence, P. A. 1992 The making of a fly. London: Blackwell.

Lee, J. J., Ekker, S. C., von Kessler, D. P., Porter, J. A., Sun, B. I. \& Beachy, P. A. 1994 Autoproteolysis in hedgehog protein biogenesis. Science, Wash. 266, 1528-1537.

Luk, S. K.-S., Kilpatrick, M., Kerr, K. \& McDonald, P. M. 1994 Components acting in localization of ibicoid mRNA are conserved among Drosphila species. Genetics, Princeton 137, 521-530.

Maddison, W. P. \& Maddison, D. R. 1992 MacClade: analysis of phylogeny and character evolution. Version 3.01, Sunderland, Massachusetts: Sinauer.

Marshall, H., Studer, M., Pöpperl, H., Aparicio, S., Kuroiwa, A., Brenner, S. \& Krumlauf, R. 1994 A conserved retinoic acid response element required for early expression of the homeobox gene Hoxb-1. Nature, Lond. 370, 567-571.

Marx, J. 1992 Homeobox genes go evolutionary. Science, Wash. 255, 399-401.

Meyer, A. 1993 a Evolution of mitochondrial DNA in fishes. In Biochemistry and molecular biology of fishes, vol. 2. (ed. P. W. Hochachka \& T. P. Mommsen), pp. 1-38. London, New York and Amsterdam: Elsevier.

Meyer, A. $1993 b$ Molecular phylogenetic studies of fishes. 
In Genetics and evolution of aquatic organisms. (ed. A. Beaumont), pp. 219-249, London: Chapman and Hall.

Meyer, A., Biermann, C. H. \& Orti, G. 1993 The phylogenetic position of the zebrafish (Danio rerio), a model system in developmental biology: an invitation to the comparative method. Proc. R. Soc. Lond. B. 252, 231-236.

Moav, B., Liu, Z., Gladovic, L. C., Gross, M., Faras, A. J. \& Hackett, P. B. 1993 Regulation of expression of transgenes in developing fish. Transgenic Res. 2, 153-161.

Mullins, M. G., Hammerschmidt, M., Haffter, P. \& Nüsslein-Volhard, C. 1994 Large-scale mutagenesis in the zebrafish: in search of genes controlling development in a vertebrate. Curr. Biol. 4, 189-202.

Murray, J. D. 1989 Mathematical biology. Berlin: Springer Verlag.

Murtha, M. T., Leckman, J. F. \& Ruddle, F. H. 1991 Detection of homeobox genes in development and evolution. Proc. natn. Acad. Sci. U.S.A. 88, 10711-10715.

Njølstad, P. R. \& Fjose, A. 1988 In situ hybridization patterns of zebrafish homeobox genes homologous to Hox2.1 and En-2 of mouse. Biochem. Biophys. Res. Commun. 157, $426-432$.

Nüsslein-Volhard, C. 1994 Of flies and fishes. Science, Wash. 266, 572-574

Nüsslein-Volhard, C. \& Wieschaus, E. 1980 Mutations affecting segment number and polarity in Drosophila. Nature, Lond. 287, 795-803.

Patel, N. H. 1994 Developmental evolution: insights from studies of insect segmentation. Science, Wash. 266, 581-589.

Patterson, C. 1988 Homology in classical and molecular biology. Molec Biol. Evol. 5, 603-625.

Petrovicky, I. 1966 Hybridization between Brachydanio rerio (Hamilton-Buchanan) and Brachydanio frankei Meinken. Ichthyologica 37, 3-62.

Postlethwait, J. H. et al. 1994 A genetic linkage map for the zebrafish. Science, Wash. 264, 699-703.

Raff, R. A. 1992 Direct-developing sea urchins and the evolutionary reorganization of early development. BioEssays 14, 211-218.

Raff, R. A. \& Kaufman, T. C. 1983 Embryos, genes, and evolution. The developmental-genetic basis of evolutionary change. New York: Macmillan.

Rainboth, W. 1991 Cyprinids of South East Asia. In Cyprinid fishes: systematics, biology and exploitation (ed. I. J. Winfield \& J. S. Nelson), pp. 156-202. New York: Chapman and Hall.

Runstadler, J. A. \& Kocher, T. D. 1991 A new antennapediaclass gene from the zebrafish. Nucl. Acid. Res. 19, 5434.

Saitou, H. \& Nei, M. 1987 The neighbor-joining method: a new method for reconstructing phylogenetic trees. Molec. Biol. Evol. 4, 406-425.

Schreitmüller, W. 1926 Ein Bastard von Brachydanio rerio (Zebrabarbe) $\times$ Danio malabaricus Jerdon. Blätter für Aquarienkunde 37, 440-441.

Schubert, F. R., Nieselt-Struwe, K. \& Gruss, P. 1993 The antennapedia-type homeobox genes have evolved from three precursors separated early in metazoan evolution. Proc. natn. Acad. Sci. U.S.A. 4, 143-147.
Scott, M. P. \& Carroll, S. B. 1987 The segmentation and homeotic gene network in early Drosophila development. Cell 51, 689-698.

Smith, M., Hickman, A., Amanze, D., Lumsden, A. \& Thorogood, P. 1994 Trunk neural crest origin of caudal fin mesenchyme in the zebrafish Brachydanio rerio. Proc. $R$. Soc. Lond. B 256, 137-145.

Solnica-Krezel, L., Schier, A. F. \& Driever, W. 1994 Efficient recovery of ENU-induced mutations from the zebrafish. Genetics, Princeton 136, 1401-1420.

Sommer, R. J. \& Sternberg, P. W. 1994 Changes of induction and competence during the evolution of vulva development in nematodes. Science, Wash., 265, 115-118.

Sommer, R.J. \& Tautz, D. 1993 Involvement of an orthologue of the Drosophila pair-rule gene hairy in segment formation of the short germ-band embryo of Tribolium (Coleoptera). Nature, Lond. 361, 448-450.

Strathmann, R. R., Fenaux, L. \& Strathmann, M. F. 1992 Heterochronic developmental plasticity in larval sea urchins and its implications for evolution of nonfeeding larvae. Evolution 46, 972-986.

Swofford, D. L. 1991 Phylogenetic analysis using parsimony (PAUP version 3.0s). Champaign: Illinois Natural History Survey.

Tabin, G. J. 1992 Why we have (only) five fingers per hand: Hox genes and the evolution of paired limbs. Development 116, 289-296.

van Haut, H. 1953 Über die Embryonalentwicklung der Schillerbarbe, Brachydanio albollineatus. Ph.D. thesis, University of Bonn.

Waddington, C. H. 1957 The strategy of genes. London: Allen and Unwin.

Walker, C. \& Streisinger, G. 1983 Induction of mutations by $\gamma$-rays in pregonial germ cell of zebrafish embryos. Genetics, Princeton 103, 125-136.

Wake, D. B. 1995 Evolutionary developmental biologyprospects for an evolutionary synthesis at the developmental level. Proc. Calif. Acad. Sci. (In the press.)

Weber, M. \& de Beaufort, L. F. 1916 The fishes of the IndoAustralian Archipelago. Leiden: E. J. Brill.

Westerfield, M. 1989 The zebrafish book: a guide for the laboratory use of zebrafish (Brachydanio rerio). Eugene: University of Oregon Press.

White, J. A., Boffa, M. B., Jones, B. \& Petkovich, M. 1994 A zebrafish retinoic acid receptor expressed in the regenerating caudal fin. Development 120, 1861-1872.

Wray, G. A. \& Bely, A.E. 1995 The evolution of echinoderm development is driven by several distinct factors. Development 97-106 (Suppl.).

Wray, G. A. \& Raff, R. A. 1991 The evolution of developmental strategy in marine invertebrates. Trends Ecol. Evol. 6, 45-50.

Wray, G. A. 1992 Rates of evolution in developmental processes. Am. Zool. 32, 123-134.

Zhang, W.-D., Zhao, B., Yao, J.-H., Zhou, J.-H. \& Wang, Q. 1992 Laser induced fusion of fertilized eggs of different fish families-zebrafish and loach. J. Ocean. Univ. Qingdao 22(3), 11-17. 